\title{
Cost-benefit Analysis of the KiVa Anti-bullying Program in the Netherlands
}

\author{
Gijs Huitsing $^{1,2}$ (1) $\cdot$ Simone Iris Barends ${ }^{1} \cdot$ Joran Lokkerbol $^{3}$
}

Published online: 5 July 2019

(C) The Author(s) 2019

\begin{abstract}
This study performs a cost-benefit analysis of the implementation of the KiVa anti-bullying program in the Netherlands. Specifically, it addressed whether the expected benefits of KiVa for victims in terms of lifetime income are greater than the costs that are made for implementing the program. The KiVa intervention was examined in a randomized controlled trial in the Netherlands in 2012-2014 in 98 Dutch primary schools (target grades US-level 3-4, 8 to 9 years old). A model-based approach was applied to the effects for the expected income for prevented victims, which is a long-term outcome that can be quantified. The estimated costs and benefits of implementing KiVa were used to estimate the return-on-investment (ROI) that indicated the expected benefits per euro invested. Investing in KiVa in the Netherlands generated an ROI of $€ 4.04 € 6.72$, indicating that it is good value for money to invest in KiVa. The chosen estimates in this study were deemed conservative; on the cost side, it was assumed that schools maximally implement KiVa (thus, maximum costs), and on the benefit side, only the expected income effect for victims was included to the model. Quantifying and incorporating other outcomes (i.e., depression, anxiety, psychiatric problems, not only for victims but also for bullies, bystanders, parents, teachers) may further increase the ROI for this intervention.
\end{abstract}

Keywords Anti-bullying program $\cdot$ Bullying victimization $\cdot$ Cost-benefit $\cdot$ KiVa $\cdot$ Prevention $\cdot$ Return-on-investment

\section{Introduction}

Bullying in schools remains a major problem with serious short- and long-term consequences for victims, bullies, bystanders, teachers, and parents (Arseneault 2018; Copeland et al. 2013; Wolke and Lereya 2015) with staggering costs for societies (Kline and Lewis 2018). Many anti-bullying programs have been developed and tested for effectiveness in the past decades (see for recent overviews: Gaffney et al. 2018; see also Farrington et al. 2017; Yeager et al. 2015). In addition to the important question whether anti-bullying programs are effective, it is also necessary to examine whether benefits of

Gijs Huitsing

g.e.huitsing@rug.nl; http://www.rug.nl/staff/g.e.huitsing

1 Department of Sociology, University of Groningen, Groningen, The Netherlands

2 Interuniversity Center for Social Science Theory and Methodology (ICS), Groningen, The Netherlands

3 Centre of Economic Evaluation \& Machine Learning, Netherlands Institute of Mental Health and Addiction, Utrecht, The Netherlands interventions exceed the costs. Cost-benefit analyses can be seen from an individual perspective (positive changes, increased performance), the organizational perspective (whether direct costs, such as materials and time investments, are exceeded by organizational benefits), or the societal perspective (whether the costs are smaller than benefits for society as a whole) (Aguinis and Kraiger 2009). Economic evaluations of anti-bullying programs are relatively new, and started with a discrete choice experiment in Sweden on the willingness to pay to reduce school bullying (Persson and Svensson 2013). This study contributes to this literature by examining the costbenefit ratio of the KiVa anti-bullying program in the Netherlands from a societal perspective. It is relevant to investigate whether societal efforts made to reduce bullying (i.e., governmental investments in education) generate societal benefits.

\section{Bullying and Its Consequences}

Bullying can be defined as systematic, hurtful, and goaldirected negative behavior characterized by a power difference between bullies and victims (Olweus 1993; Volk et al. 
2014). As such, bullying has negative consequences for different actors in both the short and long term. Obviously, bullying has negative consequences for victims. Bullying negatively impacts their psychosocial well-being, mental, and physical health, as well as their functioning at school or work (see for reviews: Arseneault 2018; Gini and Pozzoli 2013; McDougall and Vaillancourt 2015). For example, these reviews documented that victims are more likely to experience depressive symptoms, social anxiety, lower self-esteem, selfmutilation, suicidal thoughts, and health complaints such as stress, chronic headaches, inflammation, and reduced cortisol regulation. At school, victims of bullying feel insecure, have lower school performance, and are at increased risk of playing truant (Arseneault 2018). Victims of bullying in childhood are more at risk for unemployment, lower income, and poverty later in life (Brimblecombe et al. 2018).

Bullies also run a greater risk of a problematic development. Bullies are more likely to be involved in delinquency and violence, and are at greater risk of psychiatric problems and alcohol abuse in the long term (Copeland et al. 2013; Kretschmer et al. 2018; Ttofi et al. 2012). Bystanders of bullying risk to experience in the short-term mental health problems, negative feelings, and stress (Nishina and Juvonen 2005; Rivers et al. 2009). Most children want to intervene; however, they often do not know how, and may withhold support because they fear retaliation (Frey et al. 2015; Huitsing et al. 2014).

In addition to students, there are also costs of bullying incurred for adults. Parents of victimized children often have feelings of anger, frustration, and powerlessness, and are concerned about bullying to protect their child (Harcourt et al. 2014; Sawyer et al. 2011), which may result in loss of productivity (Jantzer et al. 2019). Parents of victimized children are willing to change their children's school in case of bullying problems, and they are willing to pay 11 times more to reduce bullying than parents of non-victimized children (Agee and Crocker 2016). Tackling bullying reduces teaching time and can be a source of stress for teachers (Smilansky 1984); conversations about bullying issues with parents are often perceived as difficult and can lead to frustrations and misconceptions.

These detrimental consequences for victims, bullies, bystanders, parents, and teachers demonstrate the importance of effective anti-bullying interventions. If interventions can alleviate the problematic consequences for all involved, we expect to obtain positive societal benefits.

\section{KiVa Anti-bullying Program}

The KiVa anti-bullying program is a school-wide intervention that aims to enable students and teachers to tackle bullying (Salmivalli et al. 2010). KiVa is based on the theoretical insights that bullying is often the result of a group process
(Salmivalli 2010). This is, at first, supported by the participant role approach (Salmivalli et al. 1996), suggesting that many children are involved in bullying in some way, even if they do not bully themselves. Second, bullies often have a strong position in the peer group and bullying is often rewarded by social status (Reijntjes et al. 2013; Veenstra et al. 2010; Volk et al. 2012). Third, teachers are role models for preventing bullying and can stand up to it (Saarento et al. 2015; Veenstra et al. 2014).

Overall, KiVa has two aims, to prevent bullying and victimization, and to intervene in cases that have already emerged (Salmivalli et al. 2010). The prevention involves universal actions targeted at all students, with teacher training, theme lessons, virtual learning environment for students, KiVasymbols such as recess vests and posters, and information for parents (through flyers, an online booklet, and newsletters). Intervening by means of indicated actions is aimed at ongoing bullying and targeted at students who have been identified as targets or perpetrators of bullying (see for more information: Huitsing et al. 2019).

The effectiveness of KiVa was studied in a randomized controlled trial in 2012-2014 in target grades 3-4 of Dutch primary schools (Dutch grades 5-6). The research into the effectiveness of KiVa in the Netherlands showed that victimization of bullying had declined significantly more at KiVa schools than at control schools, both after 1 and 2 years of implementation (Huitsing et al. 2019; see also: Kaufman et al. 2018). More specifically, the number of children who were bullied monthly, weekly, or daily at KiVa schools decreased with $64 \%$ after 2 years of implementing the intervention (compared with a 53\% decrease in control schools).

\section{The Present Study}

We investigated the cost-benefit ratio of the KiVa antibullying program in the Netherlands from a societal perspective, and we aimed to answer the question to what extent the decrease in victimization is associated with societal benefits. In other words, do the benefits of reducing victimization by bullying exceed the costs that were made to implement the KiVa program?

We specifically focused on the implementation of KiVa in the Netherlands. The KiVa anti-bullying program is used worldwide in several countries (Herkama et al. 2017, see www.kivaprogram.net for dissemination). There may be subtle differences in the way KiVa is implemented in each country (for example, the extent to which teachers are trained in providing KiVa lessons), and there are definitely differences in the costs incurred for the program (for example, differences in teacher salaries). For a cost-benefit analysis, it is therefore relevant to focus on the implementation in one country separately, although the results may be transferable to nations with similar contexts (such as Europe and 
North America). For the cost-benefit ratio from a societal perspective, it was investigated whether the expected benefits of KiVa in terms of lifetime income for prevented victims are greater than the costs incurred for implementing and offering the program in the Netherlands.

We limited the benefits of KiVa to effects on income for victims, because this is an outcome that has been clearly quantified in previous research (Brown and Taylor 2008). A human capital perspective perceives income as an indication of productivity for society, which is one of the most important contributors to national economic growth. As far as income is concerned, the idea is that implementing KiVa in schools leads to prevention and a reduction in victimization, and those students who are no longer victimized will have on average a higher income during their working life than victims of bullying. This may be a consequence of opening opportunities to take up positive pathways, such as reduced mental and physical health problems, which allows prevented victims to join societal activities. Thus, from a societal perspective, it is a positive sign if victims' lifetime income is increased. Also other benefits of reducing victimization can be expected, such as a decrease in healthcare costs and increase in well-being (see, e.g., McDaid et al. 2017). Increased productivity or reduced sickness leaves may lead indirectly to increased tax contributions, which can be seen as another contribution to society. These benefits are difficult to quantify, evidence is still uncertain, or they may be seen as precursors through positive pathways of income effects.

\section{Method}

\section{Cost-benefit Analysis}

The costs and benefits of KiVa were estimated using a modelbased cost-benefit analysis (CBA). A CBA compares the additional costs required for offering KiVa with the effects generated by KiVa, where effects are expressed in monetary units (2016 Euros) to represent benefits (Boardman et al. 2017). Benefits were then divided by costs to generate the estimated return-on-investment (ROI) associated with implementing KiVa. This ROI is similar to a cost-benefit ratio (CBR), a term commonly used in economic evaluations. We also estimated the net present value, by multiplying the difference between the expected discounted benefits and expected costs with the number of students at a school of average size.

Empirical Input on Self-reported Victimization The empirical input of the reduction of victimization as a result of KiVa was taken from the randomized controlled trial (RCT) in the Netherlands in 2012-2014. In that study, two different estimates for victimization were used (Huitsing et al. 2019). First, the global item on victimization from the Olweus' Bully-
Victim Questionnaire (Olweus 1996): "how often have you been victimized at school during the past couple of months?". Children answered on a five-point scale: $0=$ "not at all", 1 = "once or twice" (occasionally), 2 = "two or three times a month" (monthly), 3 = "about once a week" (weekly), 4 = "several times a week" (daily). For the purpose of this study, we took the percentages of dichotomized responses of children who (were) bullied not at all or occasionally (0) and children who (were) bullied at monthly, weekly, or daily (1) (Solberg and Olweus 2003). The second estimate was drawn from 10 specific comparable items from the same questionnaire concerning physical, verbal, relational, material, and cyber victimization/bullying. We took the maximum score on any of these specific items, and dichotomized it similarly to the global item. Because students had more opportunities to indicate systematic victimization with the 10 specific items, this approach resulted in a higher estimate of the prevalence obtained as compared with the global item.

\section{Costs of Implementing KiVa}

The implementation costs of KiVa (that are made once) consist of the costs for attending the so-called START-training (which takes 2 days), purchasing teaching materials, and investments of teachers' time for attending the START-training and related meetings. The costs for these components of the intervention were estimated by implementation experts. Teachers' time was valued at a rate of $€ 41.25$ per hour (see Table 1). In addition, there are (annual) costs for the use of an online monitor, follow-up meetings for schools (in-service training), and solving existing cases of bullying (i.e., indicated actions). Other annual costs are the number of hours that teachers spend on delivering KiVa theme-lessons. As the majority of the costs occurred in the first year, costs of offering KiVa were conservatively not discounted.

\section{Benefits of KiVa}

A reduction in victimization relates to an increase in income: a previous study determined that 11 -year-old victims earned $2.8 \%$ less at the age of 23 than children who were not victimized at the age of 11 , independent of their educational level (Brown and Taylor 2008). In addition, 11-year-old victims were less likely to complete schooling. This study was based on a British cohort study (the National Child Development Survey) in which participants participated six times between their 7th and 42nd age in surveys about bullying, educational performance, work, and income. It was estimated that the combined effect of less education and income was associated with a total lifetime income reduction of $\pm € 18,984$ (2016 discounted prices) per person for 11-year-old victims (Hummel et al. 2009). These costs are expected to represent a lower limit of the benefit of preventing and reducing 
Table 1 Calculating the once-only and annual costs for implementing $\mathrm{KiVa}$ in the Netherlands

$\begin{array}{lr}\text { Once-only costs } & \\ \text { Training and teaching materials (manuals) } & € 4147.36 \\ \text { Time investment } & € 3850.28 \\ \text { Total costs } & € 7997.64 \\ \text { Annual costs } & € 971.07 \\ \text { Out-of-pocket (licenses, online monitor) } & € 3705.07 \\ \text { Time investment (delivering lessons) } & € 4676.14 \\ \text { Total costs } & € 41.25 \\ \text { Hourly rate per teacher } & \\ \text { Average number of students per school } & \\ \text { Costs per student (i.e., costs divided by 224) } & € 35.70 \\ \text { Once-only costs } & \\ \text { Annually } & € 20.88 \\ \text { Total costs per student for } 8 \text { years } & \\ & \\ & \end{array}$

victimization. Benefits of KiVa were based on the discount rate of 3.5\% as applied in Hummel et al. (2009). Sensitivity analysis considered discount rates of both $3 \%$ and $4 \%$.

\section{Model Assumptions}

We made four assumptions on the long-term benefits of implementing the KiVa program. The first assumption was that the effectiveness of KiVa in the Netherlands at Dutch primary schools studied during the RCT (Huitsing et al. 2019) is representative for other Dutch schools that are using KiVa. Thus, it is assumed that comparable results will be found when KiVa is offered in future years at other Dutch primary schools that are motivated to implement an antibullying program.

The second assumption was that the effectiveness of KiVa in the Netherlands over a 2-year period will sustain with $70 \%$ in the long term (in line with Hummel et al. 2009; Knapp et al. 2011). This means that for $70 \%$ of the children for whom the bullying ended (or for whom it was prevented), victimization will not happen again. In the Netherlands, schools do not implement KiVa for enough years to verify this assumption, but research showed that Finnish KiVa schools that implemented the program for 7 years were able to decrease both the percentages of victims and bullies every year (Herkama et al. 2017). This can be seen as an indication that the likelihood of becoming a victim at KiVa schools is becoming smaller when the program is used for a longer period of time. Because of the possibility that some victims become victimized again, we set the long-term effectiveness at $70 \%$ which is in line with previous economic evaluations (Hummel et al. 2009; Knapp et al. 2011). The correction will add some cautiousness to the estimates, and we will test the impact of a more stringent sustainability percentage in sensitivity analyses.

The third assumption was that there is a causal relationship between victimization and a lower level of education as well as less income. Research supports this assumption (see for a review: Arseneault 2018), because compared with non-victims, victims of bullying in childhood have less often completed schooling and at a later age a lower income and a higher probability of unemployment (Brimblecombe et al. 2018; Brown and Taylor 2008; Takizawa et al. 2014). Although there are strong indications that these differences in income, education, and work are direct consequences of victimization of bullying, it remains possible that victims differed from non-victims in a way that also affected income and education later in life. Even in studies that controlled for family background, mental and physical health, and intelligence, there may remain other unmeasured factors that explain both victimization of bullying in childhood and the economic outcomes later in life.

The fourth assumption was that differences in expected income between victims and non-victims of bullying in childhood from the birth cohort of the National Child Development Survey (Brown and Taylor 2008) can also be applied to differences between victims and non-victims of bullying in the KiVa-cohorts in the Netherlands. The cohort study of the NCDS is one of the few that have studied participants in both childhood and adulthood. Although there are many contextual differences between cohorts, we assumed that the mechanisms linking victimization and its detrimental consequences later in life are comparable between cohorts.

Applying these assumptions introduces uncertainty, as applying other assumptions will lead to different results. To investigate to what extent the assumptions affect the results, we performed sensitivity analyses with repeated calculations. We investigated whether more conservative choices concerning assumption 2 (the extent to which a decrease in the number of victims sustains in the longer term) and assumption 3 and 4 (the estimated income per victimized student later in life, estimating whether the income effect can directly be attributed to victimization by bullying) have an effect on the estimated societal benefits. 


\section{Results}

\section{Costs of KiVa in the Netherlands}

The total cost per student for implementing KiVa in the four upper grades of primary school (US grades 3 to 6 ) is estimated at $€ 202$, see Table 1 . These costs consist of the investment that schools make for the START-training as well as the time that teachers spend for implementing KiVa for 8 years (the entire course of primary school). The once-only costs per student include the START-training, the direct cost of the KiVa materials, and the time investment for participating in the STARTtraining ( $€ 36$ per student, which is approximately $20 \%$ of the total costs). The remaining $80 \%$ consists of the time that teachers spend on implementing KiVa for 8 years $(8 \times € 20.88=€ 167)$. The time teachers spend on KiVa includes the time involved in delivering lessons, coordinating the monitor, attending meetings, and performing indicated actions.

\section{Expected Benefits of KiVa}

The expected benefits per student were estimated at $€ 818$ (global victimization item) and $€ 1362$ (10 specific items) as a result of the additional income, see Table 2 . These benefits were calculated by multiplying the expected reduction in the number of victimized students (including the $70 \%$ correction) with the expected additional income for these students. The expected benefits per student can accordingly be obtained by dividing these benefits by the average number of students per school.

\section{Return-on-Investment}

The expected benefits in terms of additional income per student are higher than the expected costs per student. The returnon-investment (ROI) for income, or the expected benefits per invested euro, is €4.04 (€818/€203) for the global victimization item and $€ 6.72$ ( $€ 1362 / € 203$ ) for the 10 specific victimization items (see bottom lines of Table 2). This means that only for the expected income of people later in life, every euro invested in $\mathrm{KiVa}$ is expected to return $€ 4.04$ (or even $€ 6.72$ ) in the long term. The expected net present value of implementing KiVa equals $€ 137,865$ ((€818-€203) × 224 students $)$ for a cohort of 224 students on an average school for the global victimization item and $€ 259,806((€ 1363-€ 203) \times 224$ students) for a similar cohort when using the 10 specific victimization items.

The difference in ROI and net present value between the global victimization items and the 10 specific items on several forms of victimization stems from the difference in prevalence (which was higher for the 10 specific items), leading to a larger average number of bullied students per school. The relative risk at KiVa schools for being bullied, as compared
Table 2 Prevalence of victimization and its association to the expected benefits of lifetime earnings for reducing victimization by bullying

\begin{tabular}{|c|c|c|}
\hline & Global victimization item & $\begin{array}{l}\text { Maximum of } 1 \\
0 \text { specific items }\end{array}$ \\
\hline \multicolumn{3}{|l|}{ Part 1: Prevalence of victimization } \\
\hline May 2012 (T1) - intervention & $35.00 \%$ & $49.40 \%$ \\
\hline May 2012 (T1) - control & $33.40 \%$ & $47.00 \%$ \\
\hline May 2014 (T5) - intervention & $12.50 \%$ & $17.60 \%$ \\
\hline May 2014 (T5) - control & $15.90 \%$ & $23.60 \%$ \\
\hline Relative risk for being bullied in the intervention condition ${ }^{1}$ & $75.02 \%$ & $70.95 \%$ \\
\hline \multicolumn{3}{|l|}{ Part 2: Relative risk in relation to expected benefits } \\
\hline Average number of victims at a school ${ }^{2}$ & 55 & 79 \\
\hline Reduction of victims at KiVa schools in the short term & 13.79 & 22.97 \\
\hline Sustainment of $70 \%^{3}$ & 9.65 & 16.08 \\
\hline Benefits for each non-victimized student & $€ 18,984.00$ & $€ 18,984.00$ \\
\hline Total benefits & $€ 183,272.00$ & $€ 305,213.00$ \\
\hline Expected benefit per student & $€ 818.18$ & $€ 1362.56$ \\
\hline Total cost per student (taken from Table 1) & $€ 202.71$ & $€ 202.71$ \\
\hline Return-On-Investment (ROI) & $€ 4.04$ & $€ 6.72$ \\
\hline
\end{tabular}


with control schools, was also somewhat lower with the 10 specific victimization items ( $71 \%$ vs. $75 \%$ with the global victimization item), leading to a larger expected reduction in the number of bullied students in both the short and long term.

\section{Sensitivity Analyses}

In the sensitivity analyses, the costs and benefits of implementing KiVa were again compared with each other, but with different values for some model parameters (see Fig. 1). These adjusted values concerned the expected benefits due to reduced victimization, the extent to which a reduction in the number of bullied students continues in the long term, and the discount rates applied to the lifetime benefits of KiVa. We provided the sensitivity analyses only for the global victimization item, which has the lowest expected ROI for income.

The first sensitivity analysis did not include the full expected benefits of $€ 18,984$ per reduced victim, but inspected what would happen to the ROI if the expected benefits are reduced. The straight line in Fig. 1 shows that when, for example, half of the expected income effect can directly be attributed to victimization by bullying, the ROI for income will be reduced to $€ 2.02$. This might be relevant, because the other half of the income reduction can be attributed to unknown factors that explain both the victimization and negative outcomes later in life. Even in this case, the ROI for income is still higher than $€ 1.00$, so also under this more stringent assumption, it is expected that investments in KiVa are seen as valuable from a societal perspective. When only $24.8 \%$ of the reduction in income can be attributed to being bullied ( $€ 4705)$, the ROI becomes equal to 1 , rendering benefits of KiVa equal to its costs.

The second sensitivity analysis investigated the impact of a more conservative assumption about the extent to which the decrease in the number of bullied students sustained. The dashed line in Fig. 1 shows that when the effect does not sustain for $70 \%$ of the helped victims (as in the main analysis), but only for half of this (35\%), the ROI for income drops to $€ 2.02$. Under this assumption too, it is therefore expected that investing in KiVa provides society with good value for money. When only $17.4 \%$ of the victims who were helped by the program remain non-victimized, the ROI becomes equal to 1 .

The combination of a $50 \%$ reduction of both the benefits per reduced victim (from $€ 18,984$ to $€ 9492$ ) and the extent to which the decline in bullying persists (from 70 to $35 \%$ ) leads to an ROI for income of $€ 1.01$. In this situation, investing in $\mathrm{KiVa}$ is expected to lead to similar benefits (in the form of

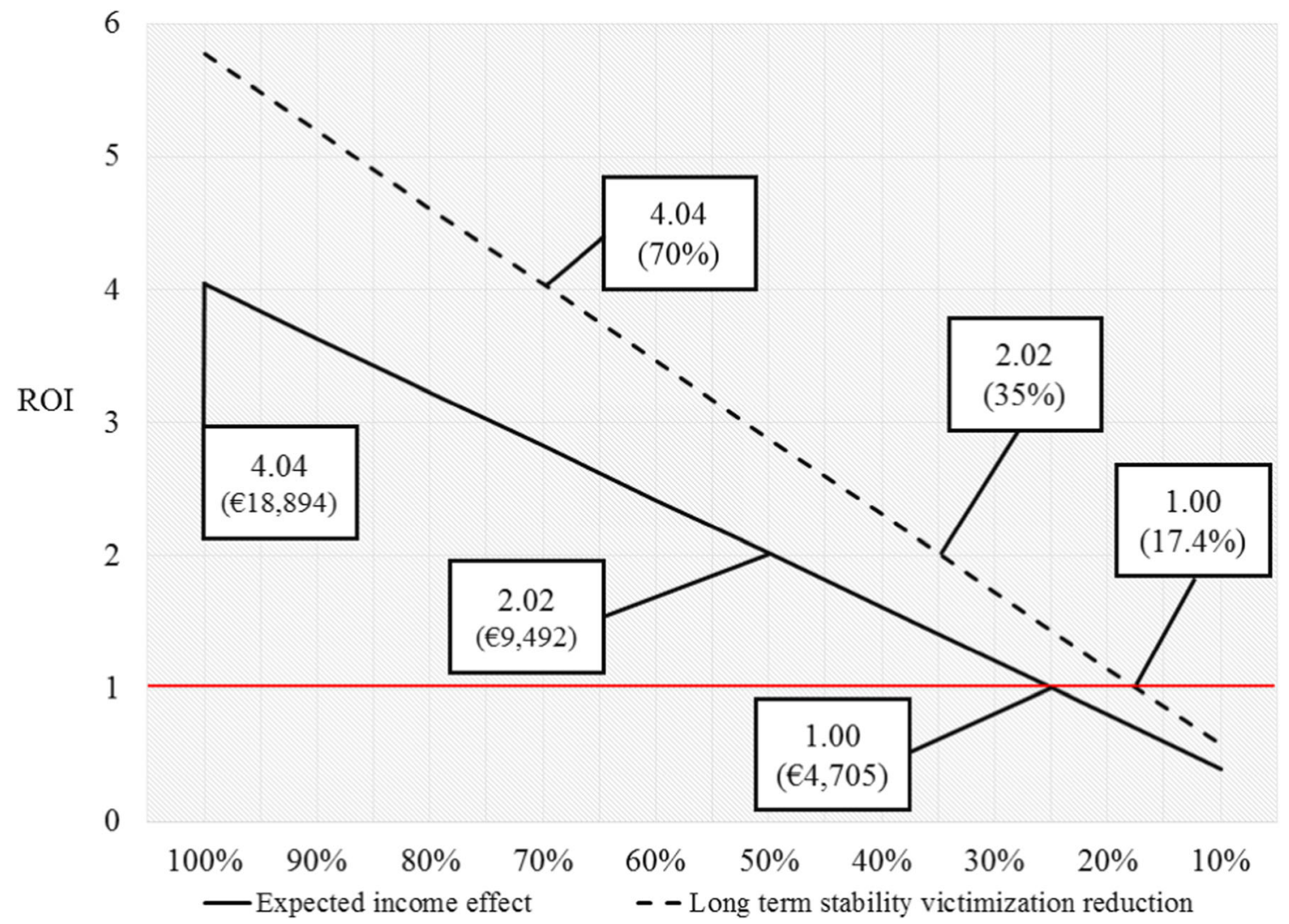

Fig. 1 Sensitivity analyses on the expected ROI. The straight line for the expected income effect is under the restriction of $70 \%$ long-term stability of victimization reduction. The dashed line for the long-term stability of

victimization reduction is under the restriction of the expected income effect of $100 \%$ 
quantifiable income) as costs for society. When this combined analysis was performed with the 10 specific victimization items, reducing both the benefits per reduced victim and the stability of the decline in bullying with $50 \%$ resulted in an ROI of $€ 1.68$, suggesting that it is still valuable to invest in KiVa.

The benefits of the intervention were based on a discount rate of $3.5 \%$ to lifetime benefits, and applying a somewhat lower discount rate of $3 \%$ would increase the ROI by an estimated $8.24 \%$. Applying a somewhat higher discount rate of $4 \%$ would decrease the ROI by an estimated $7.32 \%$.

\section{Discussion}

Calculations on the costs and benefits (in terms of income) as a result of implementing the KiVa anti-bullying program showed that it can be valuable for the Dutch society to invest in $\mathrm{KiVa}$, even if only the benefits for the later income of victims are considered. In a model-based analysis with realistic assumptions, the ROIs for victims' expected income of $€ 4.04-€ 6.72$ indicate that the expected income benefits of reducing and preventing bullying are expected to be higher than the costs that schools make to provide KiVa to their students.

Sensitivity analyses paid particular attention to reasons why the return-on-investment would yield less positive results. If the expected income effects later in life were reduced by $50 \%$, there would still be an expected positive ROI ( $€ 2.02)$. Similarly, the long-term stability of the reduction of victimization was already set to $70 \%$ (implying that $30 \%$ of the helped victims become victimized again), reducing this percentage to $35 \%$ also yielded a positive ROI (€2.02). Even with more restrictive assumptions, an investment in KiVa would generate benefits twice as large as the required investment.

\section{Conservative Model Parameters}

The models that we applied can be considered as conservative, because there are many reasons why the societal benefits may be higher. Conservative estimates, resulting in less optimistic ROI estimates, have been made on both the cost and benefit side.

When estimating the costs in the model, it was first assumed that schools maximally implement KiVa. This was modeled in terms of the number of hours that teachers spend on KiVa lessons and the number of hours they spend on training days and interpreting the KiVa monitor. It would be more realistic to assume that most schools spend few hours on KiVa than would be expected from maximum implementation. Research shows that there are indeed differences in the degree to which KiVa is implemented in schools (Ahtola et al. 2013; Sainio et al. 2019), which means that the assumption that all schools implement KiVa to a maximum can be considered as conservative. Nevertheless, we modeled for all schools maximum efforts in terms of time investments (and thus in the financial investments). In addition, the calculation of the relative risk of bullying in KiVa schools (in comparison with control schools) was based on an empirical implementation of the KiVa program in the upper grades of primary school with suboptimal implementation strategies by teachers. If all intervention schools had optimally implemented the program, the decline in bullying would probably have been stronger (Haataja et al. 2014; Swift et al. 2017). Moreover, if the program was implemented in all grades, the intervention effects might be even stronger because the main message of the intervention is repeated every school year to students, but the costs will also be higher. How this will affect the overall ROI remains to be investigated.

Schools are likely to replace an alternative anti-bullying approach for which they may incur costs when implementing KiVa. At the time of the RCT on KiVa in the Netherlands, however, there were no other validated anti-bullying programs, and there was a wide variety of anti-bullying initiatives with varying prices that schools used. Setting the cost of the alternative approach in the models at zero can be considered as a conservative estimate because the incorporation of these costs would lower the additional costs that schools made for implementing KiVa.

Also on the benefit side, conservative estimates have been made. Only one type of benefit was included in the model; the expected increase in income when bullying declines. These costs associated with bullying have been quantified in previous research (Brown and Taylor 2008). However, there are many other expected benefits if bullying is stopped in childhood, such as reduced mental health problems (depressive symptoms, anxiety, low self-esteem), reduced physical problems (less stress, headaches, inflammation), and an improvement in the social relations and quality of life (Arseneault 2018). These benefits are not only expected in the long term but also in the short term. For example, there are indications that victimization is associated with more annual direct (medical and non-medical) costs (more than $€ 5000$ difference for victims vs. non-victims), and productivity losses for parents of victims (Jantzer et al. 2019). However, it is difficult to quantify these costs over the larger spectrum of antecedents and consequences of bullying, because these aspects can be related to each other. For example, lower education and reduced income in adulthood may be the result of mental and physical problems. A recent report attempted to quantify healthcare costs in more detail, and demonstrated that the ROI for the investment in the reduction of bullying can amount to more than $€ 158$ ( $£ 140$, McDaid et al. 2017), when quantified costs such as child and adolescent mental health services, the general practitioner, self-harm, schools absenteeism, and lost home ownership are incorporated in the model.

Furthermore, a limitation was that only the long-term income benefits for victims were included to the model. A 
decrease in bullying at schools can also have positive consequences for bullies (less crime, substance use, and psychiatric problems later in life), bystanders (less short-term negative feelings and stress), parents and teachers (less stress, frustrations, and increased productivity). Less bullying problems may also be directly beneficial for schools and student performance in the short term because the pedagogical climate might improve which may foster students' school adjustment, in the form of their well-being, motivation, and achievement (Salmivalli et al. 2011). By including other effects than income for victims as well as applying the benefits to other actors (bullies, bystanders, parents and teachers) in the short term, the ROI can be expected to increase.

\section{Implications and Future Research}

The cost-benefit analysis of the KiVa program in this study showed an asymmetrical distribution of the costs and benefits. Most of the costs are made by the schools, whereas most of the benefits are on the individual or societal level (including individual mental and physical health benefits that may be expected but were not included to the model). In addition, the costs for implementing an anti-bullying program such as KiVa are made directly, whereas the expected benefits used in this study (increase in income) are determined in the long term. There are direct benefits of the use of an anti-bullying program for schools, such as a safer atmosphere in the classroom, which makes teaching less of a burden to teachers, and improvements in students' school performance, academic motivation, and school well-being (Salmivalli et al. 2011). Other direct benefits may be improvements in the satisfaction of parents. However, it can be doubted whether schools perceive these benefits as larger than the resources they have to offer (financial and time investments) for implementing a school-wide program as KiVa. Schools have many priorities and can spend their resources only once. For this reason, it could be justified that governments with a long-term perspective, on behalf of society as a whole, contribute to investments in the implementation of validated, effective anti-bullying programs such as KiVa. The return-on-investment is expected to be positive; with investments expected to return more than four times in the long term. It is well-known that investments in (early) childhood affect the productivity in later life positively (Heckman 2006).

Because the KiVa anti-bullying program is currently implemented in several countries (see www.kivaprogram.net), it is important for future research to investigate whether a positive cost-benefit ratio for KiVa can also be obtained in other countries with different empirical results and different costs for implementing the program, such as teacher salaries (see for a first attempt for Finland: Persson et al. 2018; see for the Olweus bullying prevention program: Beckman and Svensson 2015). Given that KiVa has been evaluated in
Finland in an RCT (Kärnä et al. 2011b) and nationwide (Kärnä et al. 2011a) as well as in Italy (Nocentini and Menesini 2016), it would be possible to collect all the necessary information that served as input for the models used in the current study (see for the UK: Clarkson et al. 2019). Moreover, future research may do well to quantify other expected benefits of a reduction in victimization, in addition to the income effects. Examples are mental and physical health problems for victims, and detrimental outcomes for bullies, bystanders, and adults. Some of these attempts have been made recently (Brimblecombe et al. 2018; McDaid et al. 2017; Persson et al. 2018). Another suggestion for future research is to investigate the willingness to pay to reduce bullying from the payers perspective (which can be schools or governments), to investigate how a quality adjusted life year (QALY) is valued (see Persson et al. 2018). A solid quantification of expected costs and benefits in both the short and long term may convince policy makers and school staff to invest in validated, effective anti-bullying programs. These programs have shown to improve the well-being and quality of life of many children, adolescents, and adults substantively.

\section{Compliance with Ethical Standards}

Conflict of Interest The implementation and evaluation of KiVa in the Netherlands has been financed by grants from the Dutch Ministry of Education (Onderwijs Bewijs, ODB10025). The first (G.H.) author was one of the coordinators of the implementation and evaluation. Program dissemination is done by a company (www.kivaschool.nl).The authors declare that they have no financial interest in KiVa or other conflicts of interest.

Open Access This article is distributed under the terms of the Creative Commons Attribution 4.0 International License (http:// creativecommons.org/licenses/by/4.0/), which permits unrestricted use, distribution, and reproduction in any medium, provided you give appropriate credit to the original author(s) and the source, provide a link to the Creative Commons license, and indicate if changes were made.

\section{References}

Agee, M. D., \& Crocker, T. D. (2016). Are current U.S. anti-bullying programs net beneficial to parents? Inferences from school switching. Journal of Benefit-Cost Analysis, 7, 434-458. https:// doi.org/10.1017/bca.2016.21

Aguinis, H., \& Kraiger, K. (2009). Benefits of training and development for individuals and teams, organizations, and society. Annual Review of Psychology, 60, 451-474. https://doi.org/10.1146/annurev.psych. 60.110707.163505.

Ahtola, A., Haataja, A., Kärnä, A., Poskiparta, E., \& Salmivalli, C. (2013). Implementation of anti-bullying lessons in primary classrooms: how important is head teacher support? Educational Research, 55, 379-392. https://doi.org/10.1080/00131881.2013. 844941 .

Arseneault, L. (2018). Annual research review: the persistent and pervasive impact of being bullied in childhood and adolescence: 
implications for policy and practice. Journal of Child Psychology and Psychiatry, 56, 405-421. https://doi.org/10.1111/jcpp.12841.

Beckman, L., \& Svensson, M. (2015). The cost-effectiveness of the Olweus Bullying Prevention Program: results from a modelling study. Journal of Adolescence, 45, 127-137. https://doi.org/10. 1016/j.adolescence.2015.07.020

Boardman, A. E., Greenberg, D. H., Vining, A. R., \& Weimer, D. L. (2017). Cost-benefit analysis: concepts and practice. Cambridge: Cambridge University Press.

Brimblecombe, N., Evans-Lacko, S., Knapp, M., King, D., Takizawa, R., Maughan, B., \& Arseneault, L. (2018). Long term economic impact associated with childhood bullying victimisation. Social Science \& Medicine, 208, 134-141. https://doi.org/10.1016/j.socscimed.2018. 05.014 .

Brown, S., \& Taylor, K. (2008). Bullying, education and earnings: evidence from the National Child Development Study. Economics of Education Review, 27, 387-401. https://doi.org/10.1016/j. econedurev.2007.03.003

Clarkson, S., Charles, J. M., Saville, C. W. N., Bjornstad, G. J., \& Hutchings, J. (2019). Introducing KiVa school-based antibullying programme to the UK: a preliminary examination of effectiveness and programme cost. School Psychology International. https://doi. org/10.1177/0143034319841099.

Copeland, W. E., Wolke, D., Angold, A., \& Costello, E. J. (2013). Adult psychiatric outcomes of bullying and being bullied by peers in childhood and adolescence. JAMA Psychiatry, 70, 419-426. https://doi. org/10.1001/jamapsychiatry.2013.504.

Farrington, D. P., Gaffney, H., Lösel, F. A., \& Ttofi, M. M. (2017). Systematic reviews of the effectiveness of developmental prevention programs in reducing delinquency, aggression, and bullying. Aggression and Violent Behavior, 33, 91-106. https://doi.org/10. 1016/j.avb.2016.11.003.

Frey, K. S., Pearson, C. R., \& Cohen, D. (2015). Revenge is seductive, if not sweet: why friends matter for prevention efforts. Journal of Applied Developmental Psychology, 37, 25-35. https://doi.org/10. 1016/j.appdev.2014.08.002.

Gaffney, H., Ttofi, M. M., \& Farrington, D. P. (2018). Evaluating the effectiveness of school-bullying prevention programs: an updated meta-analytical review. Aggression and Violent Behavior, 45, 111133. https://doi.org/10.1016/j.avb.2018.07.001.

Gini, G., \& Pozzoli, T. (2013). Bullied children and psychosomatic problems: a meta-analysis. Pediatrics, 132, 720-729. https://doi.org/10. 1542/peds.2013-0614

Haataja, A., Voeten, M., Boulton, A. J., Ahtola, A., Poskiparta, E., \& Salmivalli, C. (2014). The KiVa antibullying curriculum and outcome: does fidelity matter? Journal of School Psychology, 52, 479493. https://doi.org/10.1016/j.jsp.2014.07.001.

Harcourt, S., Jasperse, M., \& Green, V. A. (2014). "We were sad and we were angry": a systematic review of parents' perspectives on bullying. Child \& Youth Care Forum, 43, 373-391. https://doi.org/10. 1007/s10566-014-9243-4.

Heckman, J. J. (2006). Skill formation and the economics of investing in disadvantaged children. Science, 312, 1900-1902. https://doi.org/ 10.1126/science.1128898.

Herkama, S., Saarento, S., \& Salmivalli, C. (2017). The KiVa antibullying program: lessons learned and future directions. In P. Sturmey (Ed.), The Wiley handbook of violence and aggression. New York: Wiley.

Huitsing, G., Snijders, T. A. B., Van Duijn, M. A. J., \& Veenstra, R. (2014). Victims, bullies, and their defenders: a longitudinal study of the coevolution of positive and negative networks. Development and Psychopathology, 26, 645-659. https://doi.org/10.1017/ S0954579414000297.

Huitsing, G., Lodder, G. M. A., Browne, W. J., Oldenburg, B., van der Ploeg, R., \& Veenstra, R. (2019). A large-scale replication of the effectiveness of the KiVa antibullying program: a randomized controlled trial in the Netherlands. In Progress.
Hummel, S., Naylor, P., Chilcott, J., Guillaume, L., Wilkonson, A., Blank, L., et al. (2009). Cost-effectiveness of universal interventions which aim to promote emotional and social wellbeing in secondary schools. Sheffield: School of Health and Related Research (ScHARR).

Jantzer, V., Schlander, M., Haffner, J., Parzer, P., Trick, S., Resch, F., \& Kaess, M. (2019). The cost incurred by victims of bullying from a societal perspective: estimates based on a German online survey of adolescents. European Child \& Adolescent Psychiatry, 28, 585594. https://doi.org/10.1007/s00787-018-1224-y .

Kärnä, A., Voeten, M., Little, T. D., Poskiparta, E., Alanen, E., \& Salmivalli, C. (2011a). Going to scale: a nonrandomized nationwide trial of the KiVa antibullying program for grades 1-9. Journal of Consulting and Clinical Psychology, 79, 796-805. https://doi.org/ 10.1037/a0025740.

Kärnä, A., Voeten, M., Little, T. D., Poskiparta, E., Kaljonen, A., \& Salmivalli, C. (2011b). A large-scale evaluation of the KiVa antibullying program: grades 4-6. Child Development, 82, 311330. https://doi.org/10.1111/j.1467-8624.2010.01557.x.

Kaufman, T. M. L., Kretschmer, T., Huitsing, G., \& Veenstra, R. (2018). Why does a universal anti-bullying program not help all children? Explaining persistent victimization during an intervention. Prevention Science, 19, 822-832. https://doi.org/10.1007/s11121018-0906-5.

Kline, R., \& Lewis, D. (2018). The price of fear: estimating the financial cost of bullying and harassment to the NHS in England. Public Money \& Management, 28, 954-962. https://doi.org/10.1080/ 09540962.2018 .1535044$.

Knapp, M., McDaid, D., \& Parsonage, M. (2011). Mental health promotion and prevention: the economic case. London: LSE, Department of Mental Health. Retrieved June 27, 2019, from https://www.pssru. ac.uk/pub/Knapp_et_al_2011_MHPMHP-Economic-Case.pdf.

Kretschmer, T., Veenstra, R., Branje, S., Reijneveld, S. A., Meeus, W. H. J., Deković, M., Koot, H. M., Vollebergh, W. A. M., \& Oldehinkel, A. J. (2018). How competent are adolescent bullying perpetrators and victims in mastering normative developmental tasks in early adulthood? Journal of Abnormal Child Psychology, 46, 41-56. https://doi.org/10.1007/s10802-017-0316-3.

McDaid, D., Hopkin, G., Knapp, M., Brimblecombe, N., Evans-Lacko, S., \& Gan, C. (2017). The economic case for prevention in young people's mental health: bullying. London: MQ Transforming Mental Health.

McDougall, P., \& Vaillancourt, T. (2015). Long-term adult outcomes of peer victimization in childhood and adolescence. American Psychologist, 70, 300-310. https://doi.org/10.1037/a0039174.

Netherlands National Health Care Institute (2015). Kostenhandleiding: Methodologie van Kostenonderzoek en Referentieprijzen voor Economische Evaluaties in de Gezondheidszorg. Retrieved from http://tinyurl.com/NNHCI-2015. Accessed 27 June 2019

Nishina, A., \& Juvonen, J. (2005). Daily reports of witnessing and experiencing peer harassment in middle school. Child Development, 76, 435-450. https://doi.org/10.1111/j.1467-8624. 2005.00855.x.

Nocentini, A., \& Menesini, E. (2016). KiVa anti-bullying program in Italy: evidence of effectiveness in a randomized control trial. Prevention Science, 17, 1012-1023. https://doi.org/10.1007/ s11121-016-0690-z.

Olweus, D. (1993). Bullying at school: what we know and what we can do. Malden: Blackwell.

Olweus, D. (1996). The revised Olweus bully/victim questionnaire. Bergen: Research Center for Health Promotion (HEMIL center), University of Bergen.

Persson, M., \& Svensson, M. (2013). The willingness to pay to reduce school bullying. Economics of Education Review, 35, 1-11. https:// doi.org/10.1016/j.econedurev.2013.02.004.

Persson, M., Wennberg, L., Beckman, L., Salmivalli, C., \& Svensson, M. (2018). The cost-effectiveness of the Kiva antibullying program: 
results from a decision-analytic model. Prevention Science, 19, 728737. https://doi.org/10.1007/s11121-018-0893-6.

Reijntjes, A., Vermande, M., Olthof, T., Goossens, F. A., van de Schoot, R., Aleva, L., \& Van der Meulen, M. (2013). Costs and benefits of bullying in the context of the peer group: a three wave longitudinal analysis. Journal of Abnormal Child Psychology, 41, 1217-1229. https://doi.org/10.1007/s10802-013-9759-3.

Rivers, I., Poteat, V. P., Noret, N., \& Ashurst, N. (2009). Observing bullying at school: the mental health implications of witness status. School Psychology Quarterly, 24, 211-223. https://doi.org/10.1037/ a0018164.

Saarento, S., Boulton, A. J., \& Salmivalli, C. (2015). Reducing bullying and victimization: student- and classroom-level mechanisms of change. Journal of Abnormal Child Psychology, 43, 61-76. https://doi.org/10.1007/s10802-013-9841-x.

Sainio, M., Herkama, S., Turunen, T., Rönkkö, M., Kontio, M., Poskiparta, E., \& Salmivalli, C. (2019). Sustainable antibullying program implementation: school profiles and predictors. Scandinavian Journal of Psychology. https://doi.org/10.1111/sjop. 12487 .

Salmivalli, C. (2010). Bullying and the peer group: a review. Aggression and Violent Behavior, 15, 112-120. https://doi.org/10.1016/j.avb. 2009.08.007.

Salmivalli, C., Lagerspetz, K., Björkqvist, K., Österman, K., \& Kaukiainen, A. (1996). Bullying as a group process: participant roles and their relations to social status within the group. Aggressive Behavior, 22, 1-15. https://doi.org/10.1002/(SICI) 1098-2337(1996)22:1<1::AID-AB1>3.0.CO;2-T.

Salmivalli, C., Kärnä, A., \& Poskiparta, E. (2010). Development, evaluation, and diffusion of a national anti-bullying program, KiVa. In B. Doll, W. Pfol, \& J. S. Yoon (Eds.), Handbook of youth prevention science (pp. 240-454). New York: Routledge.

Salmivalli, C., Garandeau, C. F., \& Veenstra, R. (2011). KiVa antibullying program: implications for school adjustment. In A. M. Ryan \& G. W. Ladd (Eds.), Peer relationships and adjustment at school (Vol. 11, pp. 279-307). Charlotte: Information Age Publishing. https://doi.org/10.1080/17482798.2016.1233123.

Sawyer, J. L., Mishna, F., Pepler, D., \& Wiener, J. (2011). The missing voice: parents' perspectives of bullying. Children and Youth Services Review, 33, 1795-1803. https://doi.org/10.1016/j. childyouth.2011.05.010.

Smilansky, J. (1984). External and internal correlates of teachers' satisfaction and willingness to report stress. British Journal of Educational Psychology, 54, 84-92.
Solberg, M. E., \& Olweus, D. (2003). Prevalence estimation of school bullying with the Olweus Bully Victim Questionnaire. Aggressive Behavior, 29, 239-268. https://doi.org/10.1002/ab.10047

Swift, L. E., Hubbard, J. A., Bookhout, M. K., Grassetti, S. N., Smith, M. A., \& Morrow, M. T. (2017). Teacher factors contributing to dosage of the KiVa anti-bullying program. Journal of School Psychology, 65, 102-115. https://doi.org/10.1016/j.jsp.2017.07.005.

Takizawa, R., Maughan, B., \& Arseneault, L. (2014). Adult health outcomes of childhood bullying victimization: evidence from a fivedecade longitudinal British birth cohort. American Journal of Psychiatry, 171, 777-784. https://doi.org/10.1176/appi.ajp.2014. 13101401.

Ttofi, M. M., Farrington, D. P., \& Lösel, F. (2012). School bullying as a predictor of violence later in life: a systematic review and metaanalysis of prospective longitudinal studies. Aggression and Violent Behavior, 17, 405-418. https://doi.org/10.1016/j.avb.2012. 05.002 .

Veenstra, R., Lindenberg, S., Munniksma, A., \& Dijkstra, J. K. (2010). The complex relation between bullying, victimization, acceptance, and rejection: giving special attention to status, affection, and sex differences. Child Development, 81, 480-486. https://doi.org/10. 1111/j.1467-8624.2009.01411.x.

Veenstra, R., Lindenberg, S., Huitsing, G., Sainio, M., \& Salmivalli, C. (2014). The role of teachers in bullying: the relation between antibullying attitudes, efficacy, and efforts to reduce bullying. Journal of Educational Psychology, 106, 1135-1143. https://doi. org/10.1037/a0036110.

Volk, A. A., Camilleri, J. A., Dane, A. V., \& Marini, Z. A. (2012). Is adolescent bullying an evolutionary adaptation? Aggressive Behavior, 35, 222-238. https://doi.org/10.1002/ab.21418.

Volk, A. A., Dane, A. V., \& Marini, Z. A. (2014). What is bullying? A theoretical redefinition. Developmental Review, 34, 327-343. https://doi.org/10.1016/j.dr.2014.09.001.

Wolke, D., \& Lereya, S. T. (2015). Long-term effects of bullying. Archives of Disease in Childhood, 100, 879-885. https://doi.org/ 10.1136/archdischild-2014-306667.

Yeager, D. S., Fong, C. J., Lee, H. Y., \& Espelage, D. L. (2015). Declines in efficacy of anti-bullying programs among older adolescents: theory and a three-level meta-analysis. Journal of Applied Developmental Psychology, 37, 36-51. https://doi.org/10.1016/j. appdev.2014.11.005. 